\title{
The Problem of Thinking and Language: Concept
}

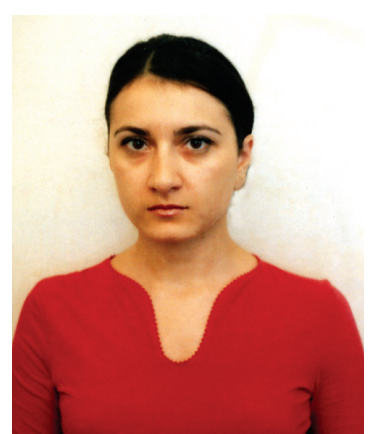

Stela Israyelyan

The paper focuses on the distinction of language and

1 thinking in the scope of conceptology.

Let us first make a clear distinction between what we know about thinking and language from what we do not know. We know that thinking is a process that takes place in the nerve nets of the brain. V. Turchin calls thinking "a stream of conscious representations". He writes, "Representations of linguistic objects, words and sentences, occupy a distinct place among all representations in the process of thinking" (Turchin 1985).

While imagining a certain word in our mind we mentally pronounce it, listen, and possibly see it written. This phenomenon is called "linguistic representation". According to V. Turchin, the stream of linguistic representations is precisely what is ordinarily called thinking. Thinking is characteristic of human beings; it is not found in animals. The so-called "abstract" thinking is actually thinking in words, the stream of linguistic representations. Without abstract thinking, the achievements of thought in which the human race takes such pride would have been impossible.

The importance of "linguistic representations" is that they are uniquely related to words and sentences as the material elements of the material system "language." This system is the aggregate of all words and sentences pronounced orally, transmitted by telephone and radio, written on paper, and so on, in short, the aggregate of what might be called the higher nervous system of the material body of culture.

As for the essential nature of language it is cognitive. We are interested in the form of language in which the human mind is completely reflected. Language functions as a means of communication, it is fashioned as a system of signs to meet the elaborate cultural and communal needs of human societies. Michael Halliday calls language "social semiotics", that is to say, language is a system of signs which are socially motivated or informed in that they have been developed to express social meanings. The meaning of a word is determined by the way this word is used in linguistic activity. Each word bears the imprint of all the sentences in which it has ever been used.

Language is a means of human communication and functions as the treasure-house of culture. Between these two phenomena, that is to say, language and culture, stands a human being. Language, culture and human beings are interconnected and interdependent, they cannot function separately. A human being sees the real world in his/her own way, represents it with the help of language the elements of which are the words that have different meanings. We have tried to draw a scheme to illustrate what has been said above: 


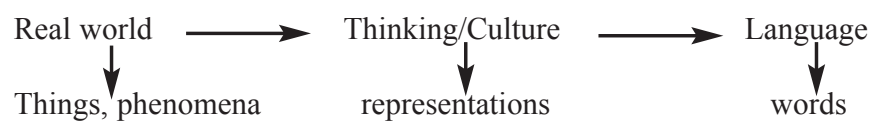

As is seen from the scheme, thinking and language are closely connected with culture. A word expresses not the thing or phenomenon of reality itself but its representation which is bound to the thinking of a human being. Language as a means of expressing culture fashions the individuality of a person, his/her mentality, behavior, etc. Words are the elements of language, representations are the elements of thinking. The interconnection and interdependence of language and culture result in the concept. Thus, a concept is an element of linguo-culturology.

One of the most desirable wishes of people is to be understood by others. In order to understand others one must know the concepts of the nation whose languages one is trying to learn. Every language has its concepts. The main components of concepts are, on the one hand, the meaning, and on the other hand, the values which can be different among various nations.

There are two main ideas when describing concepts; either we agree that each word is a concept or there must be some distinction between simple words and concepts.

A word can be a concept in one language but not in another. For example, a smile is a concept for Americans. It is well seen in the motto of the American life "Don't worry, be happy, keep smiling". But "a fixed smile" is a sign of stupidity for Armenians.

Most of the concepts that people learn and use are those that they choose from the culture in which they are brought up. The individual does not invent them, he/she acquires them in the course of communication. The invention of new concepts is much more difficult. Functionally, a stream of linguistic representations does not differ from a sequence of their material correlatives, words. In fact, it is precisely the linguistic objects which preserve and transmit information and "operate as the elements of linguistic models of reality" (Turchin 1985). Linguistic activity is taught to the child in the same way as he/she is taught to walk, to play, to wash, to eat, etc. As a result the child becomes, so to speak, plugged into the language: he uses the models already available and enriches it with new ones. So is the case with the concepts. People do not invent new concepts with ease, they rather acquire the concepts of their nations just as the words.

The words are different linguistic objects but we consider them to be carriers of a single concept because they are indistinguishable in the course of communication.

Language is a system and its concepts have meaning only as elements of the system. A word acquires its meaning by the way it is used in linguistic activity. V. Kassevich recognizes the following two functions of the concept: 1 . to serve as an element of reasoning - that is, to be a method of shaping thought. 2. to concentrate the already existing thoughts and knowledge of an object in oneself.

"This duality is a result of the system nature of the concept. The linguistic object (word), which expresses a concept is used as an element for constructing a model of reality and is associated functionally - that is, in linguistic activity (also in our imagination) - with all models in which it participates" (Kassevich 1977).

There are several general classes of concepts. Following V. F. Turchin, we distinguish two types of concepts in the scope of language and thinking problem. He says, "We have 
before us two cybernetic systems. The first system is the human brain. Its functioning is individual human thinking. Its task is to coordinate the actions of separate parts of the organism in order to preserve its existence. This task is accomplished, specifically, by creating models of reality whose material body is the nerve nets and which we therefore call neuronal models or concepts. The second system is language. Its functioning is linguistic activity in society. Its task is to coordinate the actions of individual members of society in order to preserve its existence. This task is accomplished, specifically, by creating models of reality whose material body is linguistic objects and which we therefore call linguistic models. Like the brain, language is organized hierarchically. The functional elements of this hierarchical system are the logical (linguistic) concepts" (Turchin 1985).

When a baby begins to understand speech and talk he/she acquires initial neuronal concepts which are considered to be independent of language, and then logical concepts can be considered reflections of these initial neuronal concepts. Under the great and direct influence of language the most complex concepts are formed. The linguistic activity of the society dictates the association of representations on which these concepts are based. The concepts are plugged into the child's brain in the process of learning the language.

Thus, the linguistic system is set in motion by the human brain. Without the brain, language is dead. The brain is strongly influenced by language. The concept stands between language and thinking. Each person thinks and expresses his thoughts in his own way with the help of words. Each word, or more exactly, each notion can become a concept. One notion can be a concept in one language and not be one in another.It is connected with the culture, ethnic mentality, way of living, geography, history and many other social conditions of the given language. Our conclusion can be illustrated with the help of the following scheme:

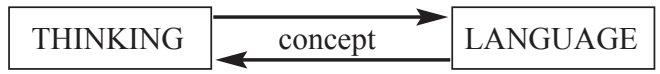

\section{References:}

1. Glushkov A.N. (ed) (1979) Cybernetics Dictionary., Kiev: URE.

2. Kassevich V.B. (1977) Elements of General Linguistics. Moscow: Nauka.

3. Turchin V.F. (1977) The Phenomenon of Science. New York: Columbia University Press.

4. Halliday M.A.K. (1976) Cohesion in English. London: Longman Group Ltd.

\section{Ltiquh lu ưunuơnnnıpjua thnjuhunuptennıpjnıGGitp. huulumgnıjp}

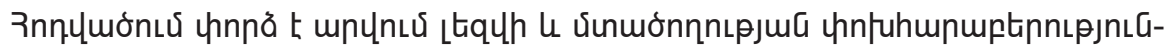

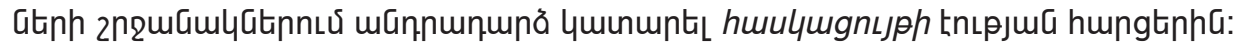

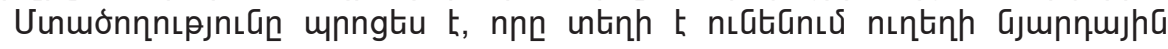

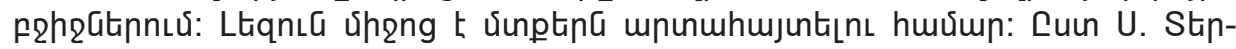

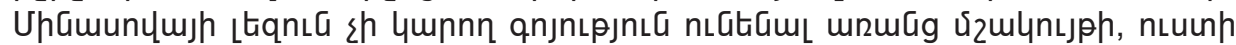

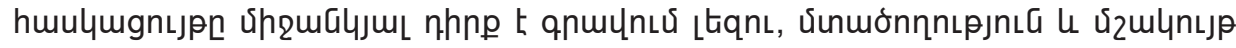
punlumgnighsGitiph upglu: 